\title{
Development and Evaluation of a Human Skin Equivalent in a Semiautomatic Microfluidic Diffusion Chamber
}

\author{
Júlia Tárnoki-Zách ${ }^{1, \dagger}$, Elod Mehes ${ }^{1, \dagger}{ }^{\dagger}$ Zsófia Varga-Medveczky ${ }^{2,+}$, Dona Greta Isai ${ }^{3}$, Nandor Barany ${ }^{4}$, \\ Edina Bugyik ${ }^{4}$, Zsolt Revesz ${ }^{5}$, Sándor Paku ${ }^{4}$, Franciska Erdo ${ }^{2, *, \ddagger}$ and Andras Czirok $1,3, *, \ddagger$
}

1 Department of Biological Physics, Eotvos University, 1117 Budapest, Hungary; zachjuli@yahoo.fr (J.T.-Z.); emehes@caesar.elte.hu (E.M.)

2 Faculty of Information Technology and Bionics, Pázmány Péter Catholic University, 1083 Budapest, Hungary; varga-medveczky.zsofia@itk.ppke.hu

3 Department of Anatomy and Cell Biology, University of Kansas Medical Center, Kansas City, KS 66160, USA; donnagreta@gmail.com

4 First Department of Pathology and Experimental Cancer Research, Semmelweis University, 1085 Budapest, Hungary; nandorbarany@gmail.com (N.B.); bedush@gmail.com (E.B.); paku.sandor@med.semmelweis-univ.hu (S.P.)

5 Revesz Plasztika, 1125 Budapest, Hungary; revesz.zsolt@dpckorhaz.hu

* Correspondence: erdo.franciska@itk.ppke.hu (F.E.); aczirok@gmail.com (A.C.)

+ These authors contributed equally to this work.

$\ddagger$ Franciska Erdo and Andras Czirok share last authorship.

Citation: Tarnoki-Zach, J.; Mehes, E. Varga-Medveczky, Z.; Isai, D.G.; Barany, N.; Bugyik, E.; Revesz, Z.; Paku, S.; Erdo, F.; Czirok, A. Development and Evaluation of a Human Skin Equivalent in a Semiautomatic Microfluidic Diffusion Chamber. Pharmaceutics 2021, 13, 910. https://doi.org/10.3390/ pharmaceutics 13060910

Academic Editors: Mireia

Mallandrich, Francisco

Fernández-Campos and

Heather Benson

Received: 21 April 2021

Accepted: 11 June 2021

Published: 20 June 2021

Publisher's Note: MDPI stays neutral with regard to jurisdictional claims in published maps and institutional affiliations.

Copyright: (c) 2021 by the authors. Licensee MDPI, Basel, Switzerland. This article is an open access article distributed under the terms and conditions of the Creative Commons Attribution (CC BY) license (https:/ / creativecommons.org/licenses/by/ $4.0 /)$.

\begin{abstract}
There is an increasing demand for transdermal transport measurements to optimize topical drug formulations and to achieve proper penetration profile of cosmetic ingredients. Reflecting ethical concerns the use of both human and animal tissues is becoming more restricted. Therefore, the focus of dermal research is shifting towards in vitro assays. In the current proof-of-concept study a three-layer skin equivalent using human $\mathrm{HaCaT}$ keratinocytes, an electrospun polycaprolactone mesh and a collagen-I gel was compared to human excised skin samples. We measured the permeability of the samples for $2 \%$ caffeine cream using a miniaturized dynamic diffusion cell ("skin-on-a-chip" microfluidic device). Caffeine delivery exhibits similar transport kinetics through the artificial skin and the human tissue: after a rapid rise, a long-lasting high concentration steady state develops. This is markedly distinct from the kinetics measured when using cell-free constructs, where a shorter release was observable. These results imply that both the established skin equivalent and the microfluidic diffusion chamber can serve as a suitable base for further development of more complex tissue substitutes.
\end{abstract}

Keywords: skin equivalent; electrospun mesh; microfluidic diffusion chamber; transepithelial transport kinetic; 3D printed device

\section{Introduction}

Topical drug administration has many advantages over per os or systemic treatments. Locally applied active compounds can be used in lower doses, often can act locally or systemically without significant adverse effects, and bypass the first pass metabolism in the liver. Several drugs are formulated as a cream, ointment, solution, suspension or even transdermal patches and are applied to the skin surface. The target effect can be dermatological (anti-inflammatory, antibiotic, anti-allergic) but topical medication may also target the central nervous system as in the case of morphine [1] or nicotine patches [2]. Several humoral therapies are also applied on the skin [3] to reduce the peripheral side effects.

In vivo animal models were widely used to test the toxicity or local irritancy of drugs, chemicals and drug formulations. In pharmaceutical testing of dermal drugs the most widely used equipment is a diffusion cell-a device which is used in various configurations: horizontal [4], vertical [5], static [6] or flow-through [7]. In the last decade diffusion 
cells were miniaturized and skin-on-a-chip devices designed, developed and fabricated (for review see [8]). These microfluidic platforms still frequently utilize excised skin samples [9,10], but organotypic cultures could be also used [11]. Some companies already started to develop ex vivo and in vitro systems to mimic skin physiology using cell cultures of keratinocytes, fibroblasts and melanocytes. The preparation of such skin substituents may involve new technologies such as electrospinning where various scaffolds are prepared to ensure the optimal mechanical properties of the artificial tissues [12] or $3 \mathrm{D}$ bioprinting [13]. These novel technologies could revolutionize not only toxicological testing but the regenerative therapy of skin diseases, burn injury and wound healing.

Ethical considerations also favor the use of skin-on-a-chip models and skin equivalents. Several countries prohibit testing of cosmetics in animals or in tissues with animal origin. In particular, the EU Directive 76/768/EEC (2004) states that Scientists in both universities and industry must be educated, trained and supported, to develop the skills to make the change to alternative, human-based testing and research systems where they are available. The acceptance and validation of non-animal methods must evolve to ensure new techniques are approved and implemented quickly [14]. These regulations as well as compliance to the $3 R$ rules (reduction, replacement and refinement of animal experiments) in cosmetic and drug testing makes it increasingly necessary to use artificial skin substituents to determine the efficacy and safety of formulations [15-19]. In this manuscript we present a simple measurement system consisting of a skin equivalent and a microfluidic diffusion chamber device. As a proof-of-concept study, we compare caffeine transport between the skin equivalent and human skin samples. We show that the presence of living cells is required to provide a transepithelial transport kinetics similar to that observed in human skin samples.

\section{Materials and Methods}

\subsection{Electrospun Membranes}

Polycaprolactone (PCL, Mw 70,000-90,000, 2-Oxepanone homopolymer, 6-Caprolactone polymer, Cat No.: 440744-500G) was purchased from Sigma-Aldrich. Formic Acid (88\%, Cat No.: A118P-500) and Acetic Acid, Glacial (Cat No.: BP2401-500) were purchased from Fisher Chemical. PCL pellets were dissolved in a 1:1 $(v / v)$ mixture of acetic acid and formic acid to yield $10 \mathrm{~mL} 15 w / v \%$ solution based on a systematic published study [20]. The solution was magnetically stirred for at least $3 \mathrm{~h}$ to completely dissolve the pellets and to get a homogeneous solution. The solution was used within $3 \mathrm{~h}$ after the solution was ready. The prepared PCL solution was placed to in a 6-mL polypropylene syringe with a $18 \mathrm{G}$ needle gauge of $1.20 \mathrm{~mm}$. The feed rate of the polymer solution was $1 \mathrm{~mL} / \mathrm{h}$, which was provided by a syringe pump. The electrospinning voltage $(26 \mathrm{kV})$ was applied to the needle at room temperature using a DC power supply. Electrospun meshes were collected on a $178 \times 100 \mathrm{~mm}$ aluminum foil (Reynolds Wrap, heavy duty) pieces, at a distance of $23 \mathrm{~cm}$ from the needle. The thickness of the membrane can be controlled by the collection time: a $3 \mathrm{~h}$ long collection yields a $100 \mu \mathrm{m}$ thick mesh weighing $150 \mathrm{mg}$.

\section{2. $3 D$ Printed Sample Holders}

Both the base and ring element of the sample holder device were fused filament deposition- (3D-) printed using polylactic acid filament (PLA, Ultimaker B.V., Utrecht, The Netherlands) and an Ultimaker Original+ printer. The base part contains a $6 \mathrm{~mm}$ wide and $2.5 \mathrm{~mm}$ tall cylinder open at both ends. The cylinder is joined to a concentric disk ( $0.5 \mathrm{~mm}$ tall, $12 \mathrm{~mm}$ wide) with a $5.5 \mathrm{~mm}$ diameter inner hole. An $8 \mathrm{~mm}$ wide electrospun membrane patch is stretched and held on the top of the sample holder by a $3 \mathrm{~mm}$ tall cone shaped ring, with $6.2 \mathrm{~mm}$ and $6 \mathrm{~mm}$ bottom and top diameters, respectively. The assembled sample holder device is disinfected in $70 \%$ ethanol for $20 \mathrm{~min}$, then dried under a sterile hood. The core of the sample holder device was filled with $75 \mu \mathrm{L}$ collagen-I gel (1.7 mg/mL, Corning, New York, NY, USA, Cat No: 354236), prepared according to the manufacturer's protocol. Briefly, collagen-I dissolved in $20 \mathrm{mM}$ acetic acid (Corning) was 
neutralized with $1 \mathrm{M} \mathrm{NaOH}$ and $10 \times$ PBS (Lonza, Basel, Switzerland) and transferred to the device at $37^{\circ} \mathrm{C}$ where gelation was completed in $30 \mathrm{~min}$. Finally, the electrospun mesh was coated by incubation with $5 \mu \mathrm{g} / \mathrm{mL}$ fibronectin (Sigma, St. Louis, MO, USA, Cat No: $\mathrm{F} 1141$ ) in PBS for $5 \mathrm{~h}$ at room temperature. The sample holder device was incubated in cell culture medium in the $\mathrm{CO}_{2}$ incubator at $37^{\circ} \mathrm{C}$ for $2 \mathrm{~h}$ before use.

\subsection{Cell Culture}

HaCaT immortalized human keratinocytes were obtained from Cell Lines Service and cultured in DMEM medium (Lonza, Cat No.: 12-604F) supplemented with 10\% FBS (Gibco Thermo Fisher, Waltham, MA, USA). Cultures were maintained in 6-well culture plates (Greiner, Frickenhausen, Germany) at $37^{\circ} \mathrm{C}$ in a humidified incubator with $5 \% \mathrm{CO}_{2}$ atmosphere. Once confluent, cell monolayers were washed in phosphate-buffered saline (PBS) twice, briefly incubated in trypsin-EDTA (Lonza), then resuspended in culture medium and transferred to the sample holder device at 1200 cells $/ \mathrm{mm}^{2}$ density. Cells attached to the fibronectin-coated electrospun membrane and formed a confluent monolayer. Cultures were maintained for various durations up to 3 weeks while the sample holder devices were kept in standard 24-well tissue culture plates (Greiner) and medium was refreshed every 3 days.

\subsection{Cell Labeling and Viability}

To monitor the health of the cultures and to live-stain the cells, the live/dead viability kit (Thermo Fisher, Waltham, MA, USA, Cat No.: L3224) was used according to manufacturer's protocol. Briefly, green-fluorescent calcein-AM was applied in $2 \mu \mathrm{M}$ concentration for $30 \mathrm{~min}$ to indicate intracellular esterase activity of live cells by conversion to a fluorescent compound in their cytoplasm. After removal of the calcein, the red-fluorescent ethidium homodimer- 1 was used at a concentration of $8 \mu \mathrm{M}$ for 20 min to indicate loss of plasma membrane integrity in dead cells where nuclei were labeled. Cell cultures double-labeled this way were imaged with epifluorescence microscopy, or fixed with $4 \%$ paraformaldehyde in PBS and transferred to cryo-sectioning.

\subsection{Histology}

For histology, cell cultures maintained on electrospun membrane were fixed with $4 \%$ paraformaldehyde in PBS. Samples were embedded in Cryomatrix resin (Thermo Fisher) and cryo-sectioned using a Cryostar NX50 cryostat (Thermo Scientific) to obtain $14 \mu \mathrm{m}$ thick sections. The samples were mounted on microscopic slides (Thermo Scientific) in Prolong mounting medium with NucBlue counterstain (Thermo Fisher) and imaged with phase contrast and epifluorescence microscopy. For semi-thin sections cell cultures were fixed in $4 \%$ paraformaldehyde $/ 1 \%$ glutaraldehyde. Samples were dehydrated in a graded series of acetone, and embedded in Spurr's resin (Sigma). Semi-thin sections were cut with a Reichert Ultracut microtome, mounted on microscopic slides (Thermo Scientific), stained with toluidine blue and imaged with brightfield microscopy.

\subsection{Microscopy}

Epifluorescence, phase-contrast or brightfield imaging was performed on a Zeiss Axio Observer Z1 inverted microscope equipped with $40 \times$ EC Plan-Neofluar objective, Colibri illumination system and Zeiss AxioCam MRm CCD camera. Images were processed using NIH ImageJ software.

\subsection{Human Skin Samples}

Human abdominal skin samples were provided by Révész Plasztika (plastic surgery clinics) and were used based on the permission for experimental application of human tissue No. 6501-6/2019/EKU. The excised skins were cleaned from subcutaneous adipose tissue and then stored frozen wrapped in an aluminium foil at $-80{ }^{\circ} \mathrm{C}$. On the day of the transdermal transport experiments the human tissue was thawed, mechanically sensitized 
with 30 fold tape strippings by an adhesive tape and cut into appropriate size to fit to the donor chamber of the microfluidic diffusion chamber device.

\subsection{Microfluidic Diffusion Cell Device}

Similarly to the traditional Franz-diffusion cell system, the polydimethylsiloxanebased microfluidic chip is also composed of three functional elements: a donor compartment where the experimental formulation is placed, the receptor compartment beneath the sample. The two compartments are separated by a skin sample or skin equivalent [9]. The diffusion surface of the sample was $1.766 \mathrm{~cm}^{2}$ and it was treated with $1000 \mu \mathrm{L}$ cream formulation by a Microman E piston gel pipette (Gilson). Contrary to generally used Franz-diffusion cells, in the microfluidic diffusion chamber provides a continuous flow of the perfusion fluid below the treated skin surface at the subcutaneous area. For studies executed on human skins peripheral perfusion fluid (PPF, $147 \mathrm{mM} \mathrm{NaCl}, 4 \mathrm{mM} \mathrm{KCl}$, and $2.3 \mathrm{mM} \mathrm{CaCl}_{2} \cdot 2 \mathrm{H}_{2} \mathrm{O}$ ) was used as an artificial extracellular fluid acceptor solution. For studies performed with skin substituents (HaCaT cell culture on mesh) cell culture medium was used as a perfusion and acceptor solution. The perfusion medium was loaded into a $5 \mathrm{~mL}$ syringe which was connected to a programmable syringe pump. Air bubbles were carefully removed from the syringe and tubes, and also from the microchannel of the chip. Flow rate was kept at $4 \mu \mathrm{L} / \mathrm{min}$ during the experiments. Collected samples were stored at $-80^{\circ} \mathrm{C}$ until spectrophotometric analysis.

\subsection{Spectrophotometry}

Caffeine content of the perfusion medium samples was determined using a NanoDrop 2000 system (Thermo Scientific) at $273 \mathrm{~nm}$ wavelength using $2 \mu \mathrm{L}$ volumes. We used a gradually diluted sequence of caffeine solutions as a calibration curve to determine sample concentrations from the absorbance values.

\subsection{Topical Formulation}

A cream containing $2 \%$ suspension of caffeine (Sigma) was used in all studies. The cream consists of paraffin oil (Semmelweis University, University Pharmacy, Budapest, Hungary) $4.1 \%$, vaseline ointment $47 \%$, propylenglycol (Hungaropharma, Budapest, Hungary) $10 \%, 0.547 \%$-citric acid solution $14 \%$ and purified water $22.9 \%$. The composition of the vaseline ointment includes polysorbate (Hungaropharma, Budapest, Hungary) $4 \%$, paraffin oil $8 \%$, vaselinum album (Hungaropharma, Budapest, Hungary) 26\%, alcohol cetylstearylicum (Molarchemicals, Halásztelek, Hungary) 12\%, propylenglycol 10\% and purified water $40 \%$.

\section{Results}

\subsection{Skin Equivalent in a Sample Holder Device}

Our skin equivalent (SE) construct models the epidermis and the connective tissue of the dermis with a layer of HaCaT keratinocytes and with a collagen gel, respectively. To provide a mechanical integrity suitable for experimental manipulations, we cultured the keratinocytes on the upper surface of an electrospun polycaprolactone (PCL) mesh, coated with fibronectin (Figure 1a). The median and mean fiber diameter of the mesh was $0.23 \pm 0.2 \mu \mathrm{m}$ and $0.26 \pm 0.2 \mu \mathrm{m}$, respectively (Figure $1 \mathrm{~b}$ ). The mesh was stretched over the orifice of a short, 3D-printed sample holder tube (Figure 1c), which was filled with collagen-I gel (Figure 1d,e). The electrospun membrane was held in place by a plastic ring, allowing to remove the membrane and the cell layer for histological analysis at the conclusion of the experiments. The geometry of the sample holder device can be adjusted to fit various experimental conditions-our samples were cultured in 24-well plates and then inserted into microfluidic Franz chamber devices for epithelial transport measurements. 

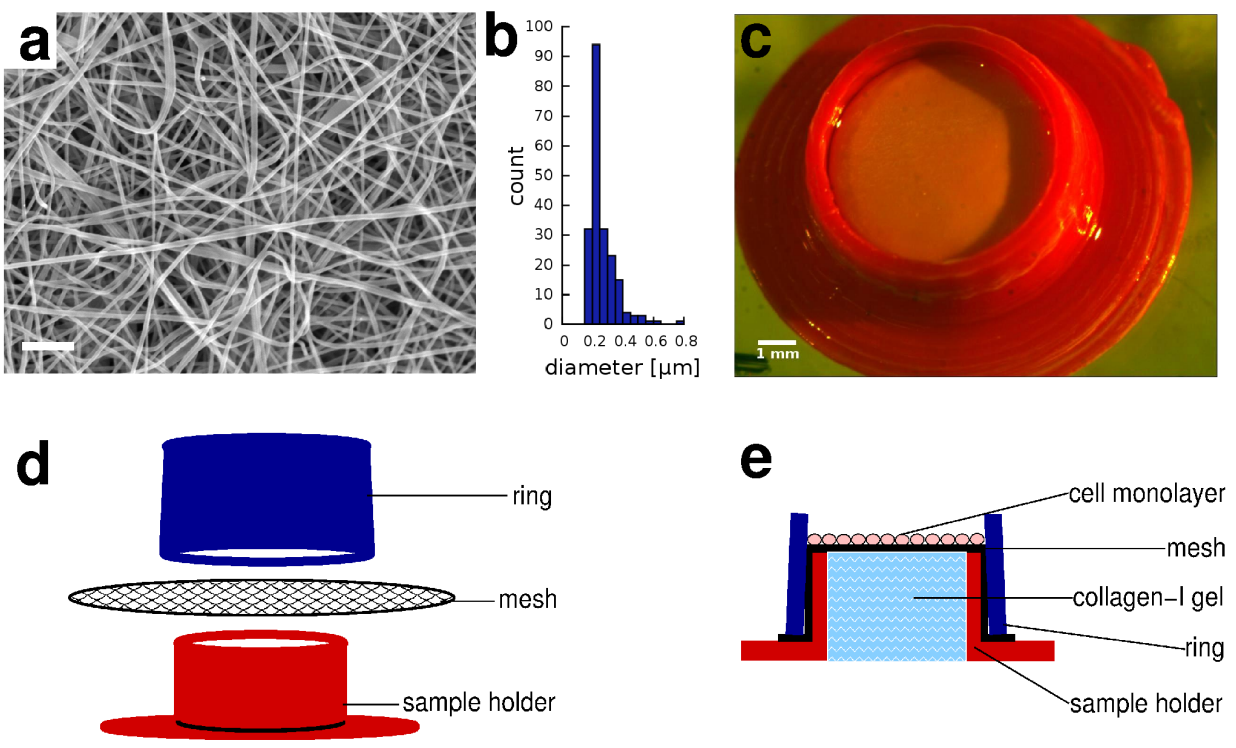

Figure 1. Skin equivalent sample holder device. (a) Scanning electron microscopic image of the electrospun PCL nanomesh consisting of filaments with sub-micron diameter. Scale bar: $3 \mu \mathrm{m}$. (b) Filament diameter distribution of the electrospun nanomesh, obtained from $n=4$ independent samples. (c) The assembled sample holder device, scale bar represents $1 \mathrm{~mm}$. (d) Schematic drawing depicting the parts of the device. (e) Schematic cross section of the assembled sample holder device. The electrospun nanomesh serves as the substrate of the cells and is stretched across the sample holder containing collagen-I gel. The mesh is hold in place by a tightly fitting cone shaped ring.

\subsection{Histology of Skin Equivalents}

$\mathrm{HaCaT}$ keratocytes readily spread on the fibronectin-coated electrospun membrane surface and form a monolayer, as visualized by calcein/ethidium ("live/dead") staining (Figure 2a). Semi-thin cross-sections reveal that the epithelium is composed of tightly connected cells (Figure $2 b$ ). When the epithelium-carrying membranes were brought to the air-liquid interface (ALI), cultures could be maintained for several weeks without substantial cell death. Frozen sections of the composite structure of the hydrogel, electrospun membrane and the epithelium reveal that in long-term ALI cultures HaCaT cells form stratified epithelia (Figure 2c,d).

\subsection{Transepithelial Transport Measurements}

For transdermal transport measurements we placed a microfluidic Franz chamber into a $\mathrm{CO}_{2}$ incubator box (Figure 3a). After establishing a steady flow of medium using a syringe pump, we positioned the skin equivalent sample above the microfluidic receptor cell and sealed the assembly with a cap that kept the epithelial layer exposed to the air and the potential pharmacological agents (Figure $3 b$ ). The transfused medium was collected and aliquoted into fractions every $30 \mathrm{~min}$.

As a proof-of-concept transdermal transport experiment, we exposed skin equivalent samples, human skin preparations and cell-free PCL membrane-covered collagen samples to caffeine cream. We collected fractions both prior and after caffeine exposure. Spectrophotometric analysis of the fractions revealed the time-course of caffeine concentration in the acceptor chamber (Figure 3c). We found that caffeine concentration reached its maximal value one hour after exposing the samples to caffeine cream in all three samples. However, while the human skin and skin equivalent samples maintained this concentration without a substantial drop for up to five hours, passive diffusion through the cell-free sample yielded a concentration peak with a half-life of $2.5 \mathrm{~h}$. We attribute this difference to the observation that the transfusion of the medium dissolved the cream in close proximity to the membrane. The ensuing gradual lack of close contact between the membrane and the cream reduced 
the transport efficiency of caffeine. Cells on the other hand, actively engaged the cream preventing the formation of gaps separating the cream from their apical surface.
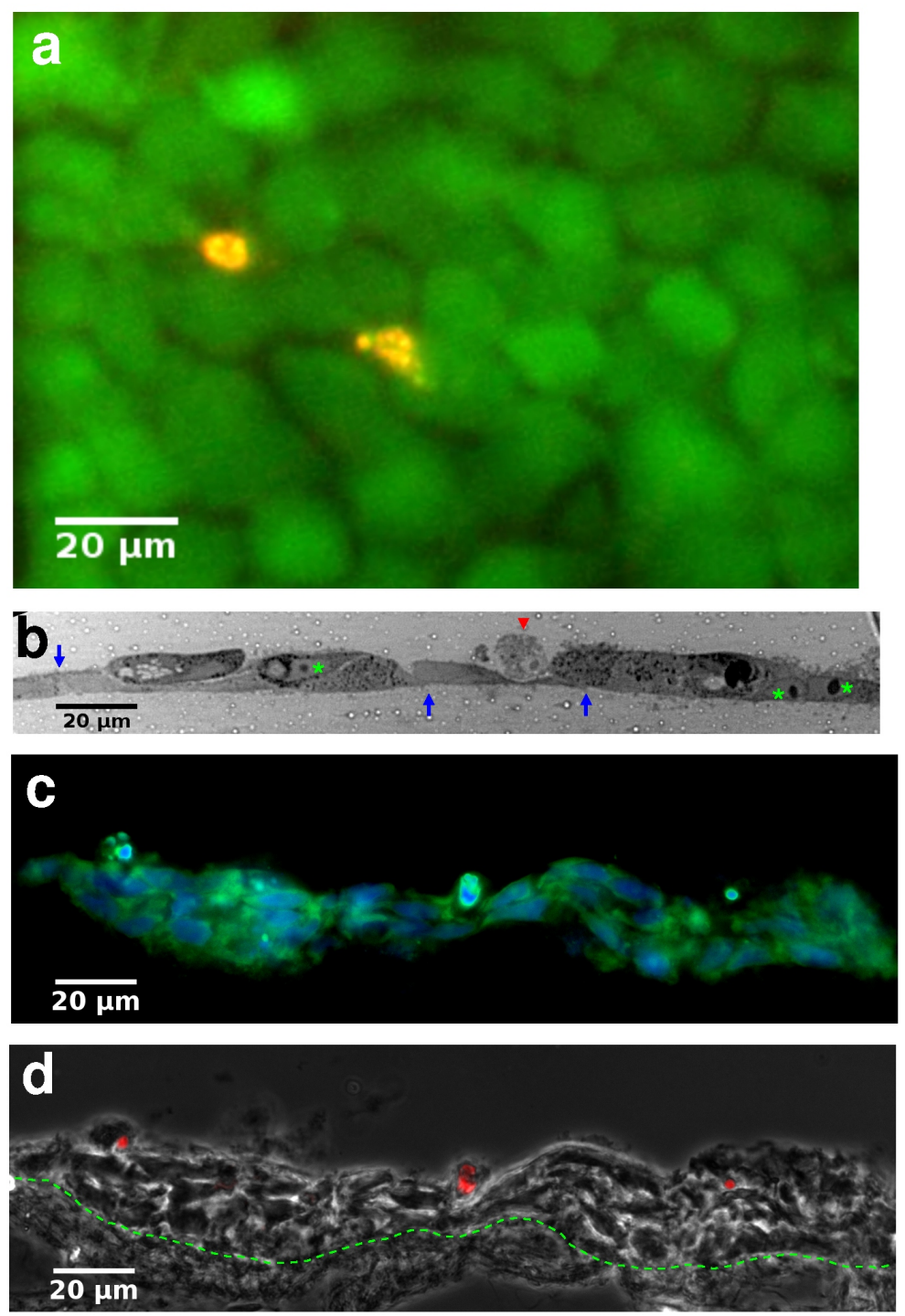

Figure 2. Histology of skin equivalents. (a) Live/dead labeled image of a monolayer of HaCaT keratocytes, imaged on the electrospun membrane at day 25 in culture. Calcein (green) fluorescence shows live cells while dead cell nuclei are identified by ethidium (red) fluorescence. Co-localization of green and red fluorescence appears as yellow. (b) Toluidine blue-stained semi-thin section of a monolayer of cells at day 18 in culture. Blue arrows point to cell-cell junctions, asterisks indicate cell nuclei with apparent nucleoli, red arrowhead marks an apoptotic cell. (c,d) Frozen cross-sections of a keratinocyte culture kept in culture for 28 days and at the air-liquid interface (ALI) for 14 days. (c) Cells and nuclei are visualized with calcein (green) and NucBlue (blue) fluorescence. (d) Phasecontrast image of the same field shown in (c) merged with ethidium fluorescence (red), identifying dead cells. Dotted line indicates the border between the cell layer and the electrospun membrane. Scale bars: $20 \mu \mathrm{m}$. 

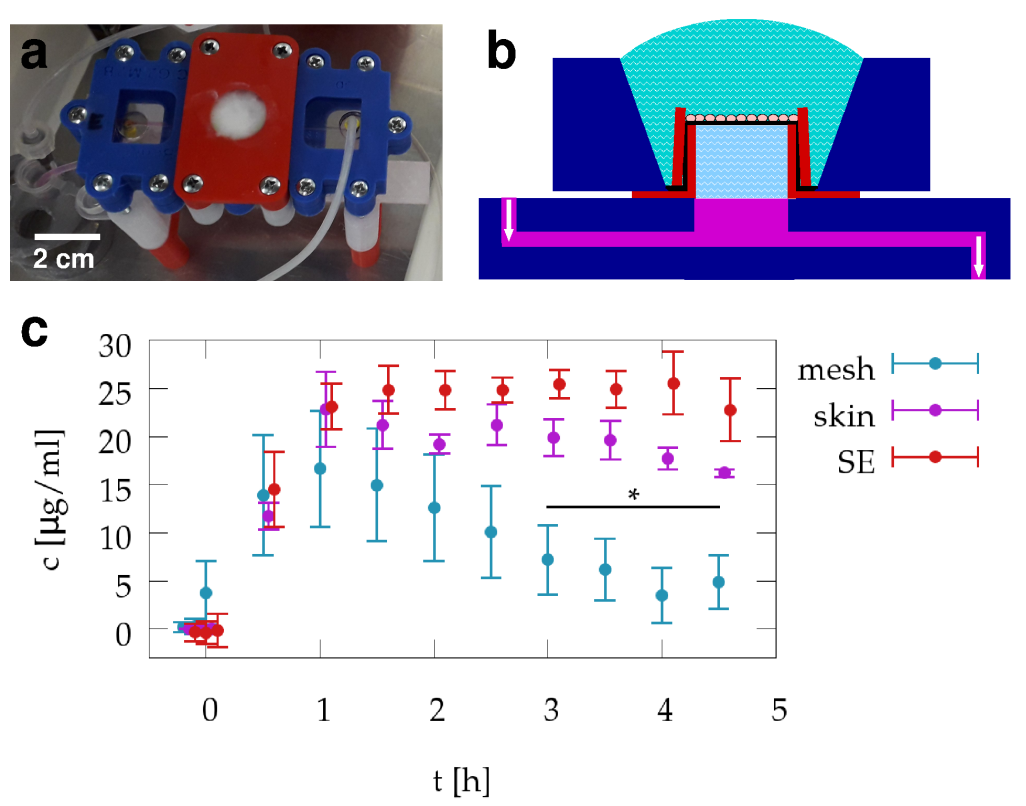

Figure 3. Transdermal transport measurements using skin equivalents and human skin. A photo (a) and schematic drawing (b) shows the sample holder device fitted into a microfluidic Franz chamber inside an incubator box. The cap of the chamber immobilized the sample holder device and held the caffeine-containing cream in close contact with the skin equivalent. Medium was transfused through the microfluidic chamber, and fractions of the medium leaving the chamber were collected every $30 \mathrm{~min}$. (c) Caffeine concentration in the collected fractions was measured by spectrophotometry and is shown as a function of time. Caffeine exposition was started at $t=0$. Red, magenta and teal colored symbols represent the average caffeine concentration obtained from the skin equivalent, human skin and cell-free samples, respectively. Error bars represent SEM, from $n=3$ independent experiments. The difference between concentration readings from the marked mesh-only and SE samples is significant ( $p=1.2 \cdot 10^{-7}, n=12$ in each group).

\section{Discussion}

Electrospun meshes provide a highly customizable substrate for tissue engineering with very promising biological properties. In particular, the diameter of electrospun fibers is similar to that of fibrous extracellular matrix (ECM). Furthermore, the large surface area of electrospun meshes facilitates cell attachment and nutrient exchange. The utilized polymer and solvent system can have profound effects on the physical properties of the electrospun meshes $[20,21]$. Our choice, polycaprolactone (PCL), is a biochemically inert, US Food and Drug Administration (FDA)-approved material, widely used in slow release drug delivery devices [22] and as suture material [23]. While the hydrophobic nature of PCL hinders cell attachment, coating with ECM proteins (like collagen) provides suitable cell adhesion sites. From the several solvent systems that has been used for PCL electrospinning, we selected one that yields very thin nanofibers in a stable and reproducible manner [20]. PCL nanofiber meshes are rather stable: a pronounced change in its material and structural properties requires several months under standard tissue culture conditions [24]. These properties make electrospun PCL nanomeshes ideal candidates for skin equivalent engineering.

The PCL mesh can adsorb and release molecules $[25,26]$, and electrospun fibers has been proposed as delivery devices for various anticancer drugs [27-31]. Importantly, caffeine release kinetics from PCL nanoparticles was recently reported to be rapid, reaching an equilibrium within an hour [32]. While this characteristic burst release of hidrophobic polymers $[33,34]$ prompted research to combine electrospun fibers with nanoparticles exhibiting a slower release kinetics for drugs [35], in our experiments the time scale of transdermal transport is longer, and the caffeine creme was provided in a great excess. Thus, our results are unlikely to be affected by direct caffeine adsorption in the PCL mesh. 
Over the past decade several attempts have been made to create human skin equivalents. Skin equivalents can model both the epidermis and dermis by combining isolated primary keratinocytes and fibroblast cells with hydrogels [36-39]. The similarity between skin equivalents and human skin samples was established by histological analyses and their functional integration was verified by implantation into immunodefficient mice [40]. Besides all its advantages, one of the known issues with this emerging tissue engineering technology is the insufficient mechanical properties of current skin equivalents. The low tensile strength of several biological hydrogels makes them difficult to use them in classic transdermal transport measurements within Franz diffusion cells [41,42]. To improve the poor mechanical properties various electrospun polymers can be used [43-45], however as yet we have not seen the utilization of this opportunity in skin equivalent engineering. Our approach proposed here combines electrospun poly-caprolactone substrate for improved mechanical stability of skin equivalents and microfluidic Franz diffusion cells for transdermal transport measurements.

The presented proof-of-concept study has several limitations. First, the epidermal and dermal layers of the skin are in reciprocal co-regulatory relationship. Keratinocytes of the epidermis influence fibroblasts of the dermal layer in a paracrine manner by producing IL-1, TNF-alpha, PDGF, TGF-beta and activin. Fibroblasts respond by producing extracellular matrix proteins and releasing KGF/FGF7, IL-6 and GM-CSF, which feeds back on the proliferation and differentiation of keratinocytes in a paracrine manner [46]. In this study we focused only on the epidermis and used serum in the culture medium to provide the survival factors for the keratinocytes. Further refinement of this technique can, however, also incorporate fibroblast cells in the collagen-I gel. A second limitation is that the hydrophilicity of the reagent is expected to have a large effect on transdermal transport, and we just investigated caffeine, a hydrophilic compound. The transdermal transport properties of caffeine are well documented, and the stratum corneum functions as the main diffusive barrier [47]. While the HaCaT cells in our skin equivalents were multi-layered in air-liquid interface cultures, they did not exhibit the characteristic hystology for the stratum corneum. We expect that primary keratocytes [36] or induced pluripotent stem cell-derived keratocytes [48] can overcome this limitation and form even better model for the epidermis. Finally, while the presented results demonstrate that transdermal transport through engineered skin equivalents can be readily measured using diffusion chambers, the establishment of quantitative equivalence requires further experiments with multiple compounds and adjustments in the culture conditions [49].

Author Contributions: Conceptualization, J.T.-Z., E.M., Z.V.-M., F.E. and A.C.; methodology, D.G.I., N.B., E.B., Z.R., S.P.; investigation, J.T.-Z., E.M., Z.V.-M.; writing, J.T.-Z., E.M., Z.V.-M., F.E. and A.C. All authors have read and agreed to the published version of the manuscript.

Funding: This work was supported by the Hungarian National Research, Development and Innovation Office (OTKA-FWF ANN 132225 to AC).

Institutional Review Board Statement: The study was approved by No. 6501-6/2019/EKU, TUKEB, Budapest, Hungary.

Informed Consent Statement: Informed consent was obtained from all subjects involved in the study.

Data Availability Statement: All relevant data is included in the manuscript.

Acknowledgments: The authors are grateful to Erika Pári (Révész Plasztika, Budapest) for providing the human excised skin samples, to István Antal and Katalin Döme (Semmelweis University, Budapest) for the kind donation and preparation of the caffeine creams.

Conflicts of Interest: The authors declare no conflict of interest. 


\section{References}

1. Argoff, C.E. Topical analgesics in the management of acute and chronic pain. Mayo Clin. Proc. 2013, 88, 195-205. [CrossRef]

2. Rasmussen, S.; Horkan, K.H.; Kotler, M. Pharmacokinetic Evaluation of Two Nicotine Patches in Smokers. Clin. Pharmacol. Drug Dev. 2018, 7, 506-512. [CrossRef]

3. Arver, S.; Stief, C.; de la Rosette, J.; Jones, T.H.; Neijber, A.; Carrara, D. A new 2 available topical preparations. Andrology 2018, 6, 396-407. [CrossRef] [PubMed]

4. Tamás, H.; Ambrus, R.; Szabóné, R.P. Investigation of permeability of intranasal formulations using Side-Bi-Side horizontal diffusion cell. Acta Pharm. Hung. 2015, 85, 19-28.

5. Salmon, D.; Gilbert, E.; Gioia, B.; Haftek, M.; Pivot, C.; Verrier, B.; Pirot, F. New easy handling and sampling device for bioavailability screening of topical formulations. Eur. J. Dermatol. 2015, 25 (Suppl. 1), 23-29. [CrossRef]

6. $\mathrm{Ng}$, S.F.; Rouse, J.J.; Sanderson, F.D.; Meidan, V.; Eccleston, G.M. Validation of a static Franz diffusion cell system for in vitro permeation studies. AAPS PharmSciTech 2010, 11, 1432-1441. [CrossRef] [PubMed]

7. Addicks, W.J.; Flynn, G.L.; Weiner, N. Validation of a flow-through diffusion cell for use in transdermal research. Pharm. Res. 1987, 4, 337-341. [CrossRef] [PubMed]

8. Ponmozhi, J.; Dhinakaran, S.; Varga-Medveczky, Z.; Fónagy, K.; Bors, L.A.; Iván, K.; Erdő, F. Development of Skin-On-A-Chip Platforms for Different Utilizations: Factors to Be Considered. Micromachines 2021, 12, 294. [CrossRef] [PubMed]

9. Lukács, B.; Bajza, Á.; Kocsis, D.; Csorba, A.; Antal, I.; Iván, K.; Laki, A.J.; Erdő, F. Skin-on-a-Chip Device for Ex Vivo Monitoring of Transdermal Delivery of Drugs-Design, Fabrication, and Testing. Pharmaceutics 2019, 11, 445. [CrossRef]

10. Bajza, Á.; Kocsis, D.; Berezvai, O.; Laki, A.J.; Lukács, B.; Imre, T.; Iván, K.; Szabó, P.; Erdő, F. Verification of P-Glycoprotein Function at the Dermal Barrier in Diffusion Cells and Dynamic "Skin-On-A-Chip" Microfluidic Device. Pharmaceutics 2020, 12, 804. [CrossRef] [PubMed]

11. Alberti, M.; Dancik, Y.; Sriram, G.; Wu, B.; Teo, Y.L.; Feng, Z.; Bigliardi-Qi, M.; Wu, R.G.; Wang, Z.P.; Bigliardi, P.L. Multi-chamber microfluidic platform for high-precision skin permeation testing. Lab Chip 2017, 17, 1625-1634. [CrossRef] [PubMed]

12. Azimi, B.; Thomas, L.; Fusco, A.; Kalaoglu-Altan, O.I.; Basnett, P.; Cinelli, P.; Clerck, K.D.; Roy, I.; Donnarumma, G.; Coltelli, M.B.; et al. Electrosprayed Chitin Nanofibril/Electrospun Polyhydroxyalkanoate Fiber Mesh as Functional Nonwoven for Skin Application. J. Funct. Biomater. 2020, 11, 62. [CrossRef] [PubMed]

13. Tarassoli, S.P.; Jessop, Z.M.; Al-Sabah, A.; Gao, N.; Whitaker, S.; Doak, S.; Whitaker, I.S. Skin tissue engineering using 3D bioprinting: An evolving research field. J. Plast. Reconstr. Aesthet. Surg. 2018, 71, 615-623. [CrossRef]

14. EU Directive 76/768/EEC. Available online: https:/ / ec.europa.eu/growth/sectors/cosmetics/legislation_en (accessed on 1 June 2021).

15. OECD. Test Guideline 427: Skin Absorption: In Vivo Method; OECD: Paris, France, 2004.

16. OECD. Test Guideline 428: Skin Absorption: In Vitro Method; OECD: Paris, France, 2004.

17. OECD. Guidance Document for the Conduct of Skin Absorption Studies; OECD Series on Testing and Assessment; OECD: Paris, France, 2004.

18. Kielhorn, J. International Programme on Chemical Safety Dermal Absorption; Environmental Health Criteria; WHO: Geneva, Swizerland, 2006.

19. U.S. EPA. Dermal Exposure Assessment: A Summary of EPA Approaches; EPA/600/R-07/040F; U.S. EPA: Washington, DC, USA, 2007.

20. Van der Schueren, L.; De Schoenmaker, B.; Kalaoglu-Altan, O.I.; De Clerck, K. An alternative solvent system for the steady state electrospinning of polycaprolactone. Eur. Polym. J. 2011, 47, 1256-1263. [CrossRef]

21. Leach, M.K.; Feng, Z.Q.; Tuck, S.J.; Corey, J.M. Electrospinning fundamentals: optimizing solution and apparatus parameters. J. Vis. Exp. 2011. [CrossRef]

22. Alonso, C.; Martí, M.; Barba, C.; Lis, M.; Rubio, L.; Coderch, L. Skin penetration and antioxidant effect of cosmeto-textiles with gallic acid. J. Photochem. Photobiol. B 2016, 156, 50-55. [CrossRef]

23. Cipitria, A.; Skelton, A.; Hutmacher, D. Design, fabrication and characterization of PCL electrospun scaffolds. J. Mater. Chem. 2011, 21, 9419-9453. [CrossRef]

24. Bölgen, N.; Menceloğlu, Y.Z.; Acatay, K.; Vargel, I.; Pişkin, E. In vitro and in vivo degradation of non-woven materials made of poly(epsilon-caprolactone) nanofibers prepared by electrospinning under different conditions. J. Biomater. Sci. Polym. Ed. 2005, 16, 1537-1555. [CrossRef]

25. Rambhia, K.J.; Ma, P.X. Controlled drug release for tissue engineering. J. Control. Release 2015, 219 , 119-128. doi:10.1016/j.jconrel.2015.08.049. [CrossRef]

26. Ravi, P.R.; Vats, R.; Dalal, V.; Gadekar, N. Design, optimization and evaluation of poly-epsilon-caprolactone (PCL) based polymeric nanoparticles for oral delivery of lopinavir. Drug Dev. Ind. Pharm. 2015, 41, 131-140. [CrossRef]

27. Zong, S.; Wang, X.; Yang, Y.; Wu, W.; Li, H.; Ma, Y.; Lin, W.; Sun, T.; Huang, Y.; Xie, Z.; et al. The use of cisplatin-loaded mucoadhesive nanofibers for local chemotherapy of cervical cancers in mice. Eur. J. Pharm. Biopharm. 2015, 93, 127-135. [CrossRef] [PubMed]

28. Xie, J.; Tan, R.S.; Wang, C.H. Biodegradable microparticles and fiber fabrics for sustained delivery of cisplatin to treat C6 glioma in vitro. J. Biomed. Mater. Res. A 2008, 85, 897-908. [CrossRef] [PubMed]

29. Shao, S.; Li, L.; Yang, G.; Li, J.; Luo, C.; Gong, T.; Zhou, S. Controlled green tea polyphenols release from electrospun PCL/MWCNTs composite nanofibers. Int. J. Pharm. 2011, 421, 310-320. [CrossRef] [PubMed] 
30. Yohe, S.T.; Herrera, V.L.M.; Colson, Y.L.; Grinstaff, M.W. 3D superhydrophobic electrospun meshes as reinforcement materials for sustained local drug delivery against colorectal cancer cells. J. Control. Release 2012, 162, 92-101. [CrossRef]

31. Ignatova, M.G.; Manolova, N.E.; Toshkova, R.A.; Rashkov, I.B.; Gardeva, E.G.; Yossifova, L.S.; Alexandrov, M.T. Electrospun nanofibrous mats containing quaternized chitosan and polylactide with in vitro antitumor activity against HeLa cells. Biomacromolecules 2010, 11, 1633-1645. [CrossRef]

32. Massella, D.; Ancona, A.; Garino, N.; Cauda, V.; Guan, J.; Salaun, F.; Barresi, A.A.; Ferri, A. Preparation of bio-functional textiles by surface functionalization of cellulose fabrics with caffeine loaded nanoparticles. IOP Conf. Ser. Mater. Sci. Eng. 2018, 460, 012044. [CrossRef]

33. Zeng, J.; Yang, L.; Liang, Q.; Zhang, X.; Guan, H.; Xu, X.; Chen, X.; Jing, X. Influence of the drug compatibility with polymer solution on the release kinetics of electrospun fiber formulation. J. Control. Release 2005, 105, 43-51. [CrossRef]

34. Garg, K.; Bowlin, G.L. Electrospinning jets and nanofibrous structures. Biomicrofluidics 2011, 5, 13403. [CrossRef]

35. Balakrishnan, P.B.; Gardella, L.; Forouharshad, M.; Pellegrino, T.; Monticelli, O. Star poly(epsilon-caprolactone)-based electrospun fibers as biocompatible scaffold for doxorubicin with prolonged drug release activity. Colloids Surf. B Biointerfaces 2018, 161, 488-496. [CrossRef]

36. Michel, M.; Auger, F.A.; Germain, L. Anchored skin equivalent cultured in vitro: a new tool for percutaneous absorption studies. In Vitro Cell. Dev. Biol. Anim. 1993, 29, 834-837. [CrossRef]

37. Auger, F.A.; Pouliot, R.; Tremblay, N.; Guignard, R.; Noël, P.; Juhasz, J.; Germain, L.; Goulet, F. Multistep production of bioengineered skin substitutes: sequential modulation of culture conditions. In Vitro Cell. Dev. Biol. Anim. 2000, 36, 96-103. [CrossRef]

38. Augustine, R. Skin bioprinting: A novel approach for creating artificial skin from synthetic and natural building blocks. Prog. Biomater. 2018, 7, 77-92. [CrossRef]

39. van Kogelenberg, S.; Yue, Z.; Dinoro, J.N.; Baker, C.S.; Wallace, G.G. Three-Dimensional Printing and Cell Therapy for Wound Repair. Adv. Wound Care 2018, 7, 145-155. [CrossRef]

40. Cubo, N.; Garcia, M.; Cañizo, J.F.D.; Velasco, D.; Jorcano, J.L. 3D bioprinting of functional human skin: Production and in vivo analysis. Biofabrication 2016, 9, 015006. [CrossRef]

41. Michel, M.; Germain, L.; Bélanger, P.M.; Auger, F.A. Functional evaluation of anchored skin equivalent cultured in vitro: percutaneous absorption studies and lipid analysis. Pharm. Res. 1995, 12, 455-458. [CrossRef]

42. Labouta, H.I.; Thude, S.; Schneider, M. Setup for investigating gold nanoparticle penetration through reconstructed skin and comparison to published human skin data. J. Biomed. Opt. 2013, 18, 061218. [CrossRef]

43. Augustine, R.; Dominic, E.A.; Reju, I.; Kaimal, B.; Kalarikkal, N.; Thomas, S. Electrospun poly(epsilon-caprolactone)-based skin substitutes: In vivo evaluation of wound healing and the mechanism of cell proliferation. J. Biomed. Mater. Res. B Appl. Biomater. 2015, 103, 1445-1454. [CrossRef]

44. Augustine, R.; Nethi, S.K.; Kalarikkal, N.; Thomas, S.; Patra, C.R. Electrospun polycaprolactone (PCL) scaffolds embedded with europium hydroxide nanorods (EHNs) with enhanced vascularization and cell proliferation for tissue engineering applications. $J$. Mater. Chem. B 2017, 5, 4660-4672. [CrossRef]

45. Zhao, X.; Sun, X.; Yildirimer, L.; Lang, Q.; Lin, Z.Y.W.; Zheng, R.; Zhang, Y.; Cui, W.; Annabi, N.; Khademhosseini, A. Cell infiltrative hydrogel fibrous scaffolds for accelerated wound healing. Acta Biomater. 2017, 49, 66-77. [CrossRef]

46. Werner, S.; Krieg, T.; Smola, H. Keratinocyte-fibroblast interactions in wound healing. J. Investig. Dermatol. 2007, 127, 998-1008. [CrossRef]

47. Luo, L.; Lane, M.E. Topical and transdermal delivery of caffeine. Int. J. Pharm. 2015, 490, 155-164. doi:10.1016/j.ijpharm.2015.05.050. [CrossRef]

48. Abaci, H.E.; Guo, Z.; Doucet, Y.; Jacków, J.; Christiano, A. Next generation human skin constructs as advanced tools for drug development. Exp. Biol. Med. 2017, 242, 1657-1668. [CrossRef]

49. Abd, E.; Yousef, S.A.; Pastore, M.N.; Telaprolu, K.; Mohammed, Y.H.; Namjoshi, S.; Grice, J.E.; Roberts, M.S. Skin models for the testing of transdermal drugs. Clin. Pharmacol. 2016, 8, 163-176. [CrossRef] 